\title{
Leibniz's Two Realms Revisited
}

\section{Citation}

McDonough, Jeffrey K. 2008. Leibniz's Two Realms Revisited. Nôus 42(4): 673-696.

\section{Published Version}

doi:10.1111/j.1468-0068.2008.00696.x

\section{Permanent link}

http://nrs.harvard.edu/urn-3:HUL.InstRepos:5130439

\section{Terms of Use}

This article was downloaded from Harvard University's DASH repository, and is made available under the terms and conditions applicable to Open Access Policy Articles, as set forth at http:// nrs.harvard.edu/urn-3:HUL.InstRepos:dash.current.terms-of-use\#OAP

\section{Share Your Story}

The Harvard community has made this article openly available.

Please share how this access benefits you. Submit a story.

\section{Accessibility}




\title{
forthcoming Nôus ...
}

\author{
Leibniz's Two Realms Revisited \\ Jeffrey K. McDonough \\ Department of Philosophy \\ Harvard University
}

\begin{abstract}
Leibniz speaks, in a variety of contexts, of there being two realms - a "kingdom of power or efficient causes” and “a kingdom of wisdom or final causes.” This essay explores an often overlooked application of Leibniz’s famous “two realms doctrine” to the natural world. The first part turns to Leibniz's work in optics for the roots of his view that nature can be seen as being governed by two complete sets of equipotent laws, with one set corresponding to the efficient causal order of the world, and the other to its teleological order. The second part offers an account of how this picture of lawful over-determination is to be reconciled with Leibniz's mature metaphysics. The third addresses a line of objection proposed by David Hirschmann to the effect that Leibniz's doctrine undermines his stated commitment to an efficient, broadly mechanical account of the natural world. Finally the fourth part suggests that Leibniz's thinking about the harmony of final and efficient causes in connection with corporeal nature may help to shed light on his understanding of the teleological unfolding of monads as well.
\end{abstract}

Introduction 
In his attempt to reconcile piety and the new science, teleology and mechanism, final causation and efficient causation, Leibniz often speaks of there being two realms - a "kingdom of power or efficient causes" and "a kingdom of wisdom or final causes." He insists that "these two kingdoms everywhere permeate each other, yet their laws are never confused and never disturbed, so that the maximum in the kingdom of power and the best in the kingdom of wisdom, take place together” (SD 24/L 442). ${ }^{1,2}$

The peaceful coexistence of both realms, Leibniz maintains, reveals itself through various harmonies found throughout his metaphysical system. One such harmony holds between "the physical realm of nature, and the moral realm of grace; that is, between God considered as designer of the machine of the universe, and God considered as monarch of the divine city of minds” (Mon 87/FW 280). This first harmony arises, Leibniz maintains, because the reward and punishment of rational souls is brought about not by miraculous intervention but rather through the order of the natural world, "so that this globe, for example, must be destroyed and restored by natural means at such times as is required by the government of minds in order to achieve the punishing of some and the rewarding of others” (Mon 88/FW 280). Another harmony arises in connection with Leibniz's solution to the mind-body problem. He famously maintains that "there is a perfect harmony between the perceptions of the monad and the motions of bodies, pre-established from the outset, between the system of efficient causes and that of final causes. And it is in that harmony that the agreement or physical union between the soul and body consists, without either of them being able to change the laws of the other” (PNG 3/FW 260).

In addition to these two well-known harmonies within Leibniz's system, there is a third instance of his two realms doctrine that is neither widely recognized nor well-understood. 
Leibniz's clearest statement of this further harmony appears in the Tentamen Anagogicum where he remarks:

I usually say that there are, so to speak, two kingdoms even in corporeal nature, which interpenetrate without confusing or interfering with each other - the realm of power, according to which everything can be explained mechanically by efficient causes when we have sufficiently penetrated into its interior, and the realm of wisdom, according to which everything can be explained architectonically, so to speak, or by final causes when we understand its ways sufficiently.” (TA 479/G 273; emphasis added)

This third harmony holds within the domain of the natural world, and is grounded for Leibniz in the existence of two complete sets of equipotent laws, with one set corresponding to the efficient causal order of the world, and the other to its teleological order. The agreement between these two sets of laws of nature in turn serves as the basis for Leibniz's view that every event in corporeal nature can, in principle, be explained either in terms of efficient or final causes.

In what follows, I propose to explore the origins, foundations, and implications of the final-efficient harmony that Leibniz posits within the natural world itself. The essay falls into four main parts. The first looks to Leibniz's much neglected work in optics for the roots of his view that the world can be seen as being governed by two complete sets of equipotent laws. The second offers an account of how this picture of lawful over-determination is to be understood in light of Leibniz's mature metaphysics. The third considers the worry that Leibniz's commitment to teleology within the order of nature undermines his commitment to efficient causal explanations, and thereby to the new science itself. Finally, the fourth part suggests that Leibniz's thinking about the harmony of final and efficient causes in connection with corporeal 
nature may help to shed light on his understanding of the teleological unfolding of monads as well.

\section{Explanatory Overdetermination in Geometrical Optics}

It is easy today to underestimate the importance of optics to seventeenth century natural philosophy. Thought of the new science often first calls to mind Galileo's experiments with descending bodies, Descartes's rules of motion and impact, and, of course, the three laws of Newton’s Mathematical Principles of Natural Philosophy. Some effort might therefore be required to remind ourselves of Galileo's discoveries with the newly invented telescope, that Descartes's first systematic work in natural philosophy was appropriately titled “The World or Treatise on Light," and that in his own time Newton's fame rested as much on his Optics as it did on his Principia.

It is likewise easy to miss the importance of Leibniz's work in optics to the development of his mature natural philosophy. Much attention has been paid to Leibniz's interest in the laws of motion, his criticisms of the Cartesian rules of impact, and his attempt to establish the conservation of vis viva. ${ }^{3}$ While these features of his scientific work help to underline his commitment to the broadly mechanical model of explanation championed by the new science, they provide little insight into Leibniz's suggestion that there is a harmony even within the corporeal world, or, indeed, into his repeated claims that final causes may be useful even in the thick of doing physics. ${ }^{4}$ To understand these aspects of his mature philosophy of science, we must look not primarily towards his mechanical studies, but rather towards his work in optics during the crucial decade or so following his years in Paris. 
The overarching theme of that work is the reconciliation of two radically different approaches to the laws of optics. ${ }^{5}$ One approach Leibniz associates with Snell and Fermat, and the way of final causes. In Fermat's quickest path principle, Leibniz sees a profound avenue into the defense of the utility of final causes even in the practice of natural philosophy. An alternative approach Leibniz associates with Descartes and his followers, and the way of efficient causes. Although in optics, no less than in mechanics, Leibniz often emphasizes his disagreements with Descartes, he nonetheless clearly takes much of the Cartesian framework for granted. Thus although he criticizes the details of Descartes's derivations of the laws of optics, he never thinks to challenge the principal assumption which underlies them, namely, that the laws of light can be derived from broadly efficient-mechanical considerations.

Leibniz’s strategy for defending the compatibility of teleological and efficient approaches to the laws of optics is most easily appreciated in the case of the law of reflection. Although the law that - in standard cases - the angle of incidence of a reflected ray of light is equal to its angle of reflection had been known since at least the time of Euclid, Descartes attempted to show how it follows from the principles of his own mechanistic physics. The proof of the law of reflection published in Descartes's Dioptrics in 1637 relies on three crucial assumptions. ${ }^{6}$ First, the behavior of a ray of light can be modeled on the behavior of material bodies, and thus can be treated as being governed by the laws of motion. Second, the motion of a ray of light can be decomposed into orthogonal motions, which can in turn be considered independently of one another, and subsequently recomposed to yield the overall motion of the body under consideration. Third, the direction of the downward component of a ray of light is reversed by a reflective surface, but is not otherwise altered, i.e. a ray of light loses none of its "speed" in rebounding off of a reflective surface. 
In an intriguing piece entitled "Metaphysical Definitions and Reflections," dated by the Academie editors to 1678-1680 (at least six years prior to the publication of the Brief Demonstration) Leibniz offers an efficient causal explanation of the law of reflection taking for granted Descartes's first two assumptions and offering a new argument for the third. Letting DBE represent a reflecting surface, $\mathrm{AB}$ an incident ray of light, and GB and HB its decomposed orthogonal components, Leibniz asks us to consider the following diagram (where DBE represents a straight line, and F represents a point some distance below B):

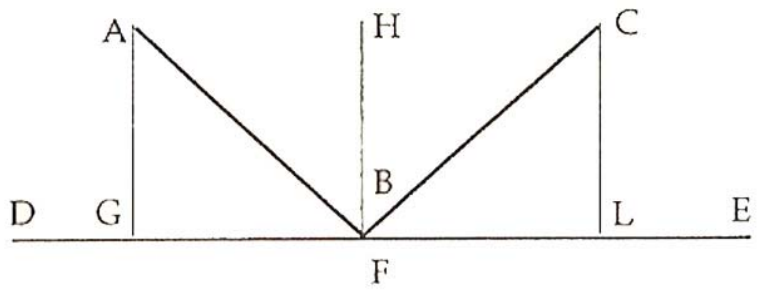

Leibniz argues that upon striking the reflecting surface, the ray of light causes the surface DBE to deform to a curve DFE so that when the surface is restored it imparts a motion BH to the ray of light. He boasts that in providing this basis for Descartes's third assumption, “we now have the reason for that which is elsewhere assumed without reason” (LC 1404/DC 255). He goes on to argue in Cartesian fashion that the horizontal component GB is unaffected by the impact with the reflective surface, and thus that the composed motions $\mathrm{GB}=\mathrm{FL}$ and $\mathrm{BH}=\mathrm{CL}$ result in the reflected ray being as $\mathrm{BC}$, and the angle of incidence $\mathrm{ABG}$ equaling the angle of reflection CBL.

More remarkable than any novelty in the preceding derivation of the law of reflection is Leibniz's claim that the same results can equally well be derived in the manner of Fermat by making use of final causes. ${ }^{7}$ Letting DE be a reflecting surface, A a source of light (e.g. a 
flashlight) and C a light sink (e.g. an eye), Leibniz sets up the problem by asking which path AMC or ABC represents the actual path of the ray of light (where $\mathrm{M}$ could be any point on the surface DE):

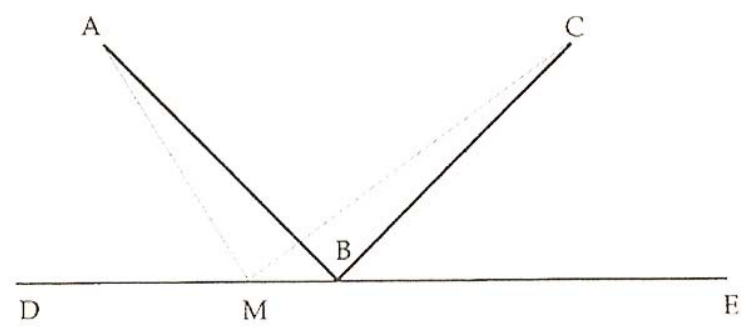

Leibniz suggests that the problem may be solved by appealing to the principle that "nature, proposing some end to itself, chooses the optimal means," and thus that - given the uniformity of the medium - "there ought to be a reason only for a long or short journey" (DC 1405/LC 255). Since there is no unique longest path, Leibniz maintains that the actual path must be the shortest, i.e. it must be $\mathrm{ABC}$ from which it also follows that the angle of incidence $\mathrm{ABD}$ must be equal to the angle of reflection CBE. Leibniz concludes that, at least for a standard class of cases, ${ }^{8}$ the path of a ray of light can be determined by calculating the shortest reflected route from its source to its sink.

In this non-Cartesian approach to the laws of optics, Leibniz sees the possibility of defending - at two different levels - the utility of appealing to final causes in doing natural philosophy. First, as he more famously argues in connection with the laws of motion and impact, Leibniz maintains that consideration of God's providential design of the world can help us to discover and explain the laws of nature themselves (e.g. DM 21, T 349). Even without grasping God's ends in detail, we might, Leibniz suggests, narrow the range of candidate laws 
for the actual world by supposing that in aiming to create an elegant and intelligible universe, God gives preference to laws that are orderly, continuous, and yield unique values for discoverable quantities such as distance, speed, and energy. Because the imposition of such constraints is grounded in assumptions about God's goal directed activity, Leibniz quite understandably sees them as the products of teleological reasoning.

Second, Leibniz maintains that the suggestion that rays of light must follow optimal paths in standard cases of reflection opens the door to teleological explanations of the behavior of rays of light. Much as we may explain, say, my taking the subway rather than a cab by appealing to the end of getting to Times Square as quickly as possible, Leibniz suggests that we may explain a ray of light's passing through point B rather than $\mathrm{M}$ by appealing to the end of getting to $\mathrm{C}$ by the quickest or shortest path possible. ${ }^{9}$ Significantly for Leibniz, in both cases a prior event - my taking the train, the light's passing through point B - is explained by appealing to a likely outcome of that event - my arriving as quickly as possible at Times Square, the light's arriving as quickly as possible at point C. Although contemporary philosophers might well argue over whether or not the explanations offered by Fermat and Leibniz are "genuinely" teleological, ${ }^{10}$ there was no such dispute among early modern natural philosophers themselves. Both the critics and champions of the Fermatian approach were in agreement that such explanations would introduce teleological explanations into natural philosophy, with Cartesians seeing this consequence as a decisive objection against them, and Leibniz seeing the reintroduction of final causes as the principal virtue of the Fermatian strategy.

Leibniz’s project of reconciling what he sees as final and efficient explanations of optical phenomena received a significant boost from his discovery of how the Cartesian and Fermatian strategies could be brought into agreement in the case of the law of refraction. Descartes had 
been the first to publish the law that the ratio of the sine of the angle of incidence to the sine of the angle of refraction is a constant determined by the media involved. ${ }^{11}$ In order to derive this result in a manner consistent with his laws of motion and impact, however, Descartes was forced to assume that light behaves as if it travels faster in denser materials - an admittedly non-intuitive consequence that he and his followers nonetheless believed could be conclusively supported by mechanistic arguments. That assumption, however, soon became a point of serious contention. For in order to argue that light takes the quickest path in cases of refraction, Fermat had to assume that light travels slower in denser materials since it is only on the assumption that light travels faster in, say, air than in water that a ray could possibly take the quickest path by traveling a greater distance in air in order to travel a lesser distance in water.

In one of his most significant scientific papers, “A Unitary Principle of Optics, Catoptrics, and Dioptrics” published in the inaugural edition of the Acta Eruditorum (1682), Leibniz attempts to address the technical difficulties separating the Cartesian and Fermatian approaches as applied to cases of refraction. On the one hand, he defends the Cartesian view that light travels faster in denser materials by arguing that denser materials are more resistant to the diffusion of light, and as a result effectively concentrate the force of rays of light so that they move more quickly than they would if they were allowed to dissipate as in less dense materials. On the other hand, Leibniz claims that light's traveling faster in denser material is consistent with the spirit, if not the letter, of Fermat's account of the law of refraction. In brief, Leibniz argues that while it is true that in standard cases of refraction a ray of light does not take the quickest path between its source and sink, nonetheless it does take the easiest path as measured by the length of the path times the resistance of the medium. This slight twist on Fermat's principle allows Leibniz to once again insist on the fundamental compatibility between deriving 
optical results from efficient principles like the laws of motion and deriving them from putatively teleological principles like Fermat’s quickest path principle.

Leibniz found still further support for his admittedly audacious conviction that natural phenomena in general might be explained either efficiently or teleologically when, in the early 1690's, he began working on a handful of problems that bore no obvious relationship to optics at all, but that nonetheless yielded to the same approach and mathematical techniques that had caught his attention in connection with optical phenomena. These problems included, most famously, the finding of the shape of freely hanging chains suspended at both ends as well as discovering the quickest path of descent for a freely falling body between two points in the vertical plane. ${ }^{12}$ Leibniz found that these problems could be solved by, as it were, considering all the possible paths or shapes that might constitute a solution, and identifying one of those paths as the actual solution by discovering a uniquely identifying property of it. He could thus maintain that just as the end of taking the optimal path could be used to underpin the claim that optical phenomena might be explained teleologically, the ends of maximizing descent or minimizing time could be used to underpin the claim that a wide variety of natural phenomena could be given teleological explanations. No proponent of the new science could, of course, doubt that phenomena such as the shapes of hanging chains, the falling of bodies, or the bending beams could, at least in principle, be explained in purely efficient terms. These cases therefore provided Leibniz with impressive, if unexpected, support for his conciliatory view that all natural phenomena could be explained by appeal to teleological laws and final causes, as well as, to mechanistic laws and efficient causes.

The empirical side of Leibniz's program has since received yet another boost from the development of mathematical physics in the eighteenth century and beyond. In 1747, 
Maupertuis introduced his principle of least action according to which "in all the changes that take place in the universe, the sum of the products of each body multiplied by the distance it moves and by the speed with which it moves is the least possible" (Maupertuis 1698-1759, 2:274). Although obscure and incomplete as it stood, the principle of least action was later clarified, developed, and set on secure mathematical foundations through the work of Euler, Lagrange, Hamilton, and Jacobi among others. Through the work of such luminaries, the pragmatic value of the approach championed by Fermat, Leibniz, and Leibniz's coterie has been placed beyond dispute, and the use of "variational principles" - the modern day descendents of the principles defended by Fermat and Leibniz - is pervasive throughout contemporary physics. It is now granted that such principles, while providing a powerful tool for solving a wide range of problems in physics, are nonetheless empirically equivalent - in the sense of yielding the same solutions to the same problems - as their non-variational counterparts. Remarkably, Leibniz's bold conjecture that a mathematically precise investigation of the natural world might follow two distinguishable - but nonetheless "parallel” - strategies has thus been supported by the development of physics since his time. ${ }^{13}$

Leibniz's work in optics and related problems provides him with a surprisingly sober route into his seemingly fantastic view that there are "two kingdoms even in corporeal nature the realm of power, according to which everything can be explained mechanically by efficient causes ... and the realm of wisdom, according to which everything can be explained architectonically, so to speak, or by final causes” (TA 479/G 273). ${ }^{14}$ One might still wonder, however, how the suggestion of lawful overdetermination might be squared with the commitments of Leibniz's mature metaphysics? Or, for that matter, how we might make sense more generally of the thought that the world is governed by two complete, and equipotent, sets of 
laws of nature? The next section will suggest that reflection on the place of the laws of nature in Leibniz's larger philosophical system offers answers to both of these questions.

\section{The Metaphysics of Lawful Overdetermination}

Even those accustomed to the boldness of Leibniz's metaphysics are prone to respond to his suggestion that there are two complete and equipotent sets of laws of nature with incredulity. ${ }^{15}$ For it might understandably be thought that the notion of two sets of laws of nature is somehow ontologically incoherent or at the very least unacceptably baroque. How or why, we might ask, are we to countenance two sets of laws of nature, when either set is by admission independently sufficient for governing all the events of the natural world?

This line of objection to Leibniz's account of explanatory overdetermination is most convincing given an ontologically robust conception of the laws of nature. Perhaps the clearest example of such a conception would be one according to which the laws of nature are themselves counted as additional, non-reducible postulates with respect to the physical world. Although Humean sympathies have in general led many philosophers today away from such a conception, Nicholas Jolley, for example, has attributed essentially such a view to Leibniz's contemporary Malebranche. According to Jolley, Malebranche's god creates the world by willing the laws of nature - themselves identified with the propositional contents of divine volitions - together with initial conditions. From these two sets of metaphysical primitives, the entire course of the world is then supposed to follow (Jolley 2002). Different, but similarly robust, conceptions of the laws of nature can be found in the work of more contemporary philosophers. ${ }^{16}$ In order to address a number of worries that appear to beset more reductive accounts, David Armstrong, for example, 
argues for identifying the laws of nature with primitive necessitating relations holding between genuine universals. If we suppose that the positing of sets of necessitating relations and sets of laws of nature march in step, we arrive at a picture that is every bit as metaphysically substantial for our concerns as the one offered by Jolley’s Malebranche.

Given such accounts of the laws of nature, we can begin to see why someone might think that the existence of two sets of equipotent laws threatens absurdity. For if we suppose that there are two sets of laws - both of which independently necessitate a given range of phenomena - we might wonder which of them does the actual necessitating? Indeed, we might see paradox lurking if we imagine that the two sets of laws happen to diverge ever so slightly. Which set of laws should we expect the phenomena to obey and why? At least some such worry appears to lie behind one commentator's striking complaint in connection with Leibniz's two realms doctrine that "even if the laws are in harmony with one another, subjects would still feel bewildered if they belonged to different realms” (Hirschmann 1988, 148).

While it is granted that the specter of two metaphysically independent sets of laws of nature might raise some intuitional hackles, it is far from clear that, by itself, it supports a concrete argument against Leibniz's unorthodox position. It is, after all, generally granted that causal overdetermination is not merely possible but indeed non-extraordinary. To borrow a standard example, it is widely granted that the breaking of a window might be overdetermined if two well-thrown bricks were to strike it at exactly the same time. Given the possible overdetermination of effects by their causes, it is difficult to see what could rule out the possibility of the overdetermination of cause-effect relations by laws of nature themselves. Diverging sets of laws would, of course, present a more serious concern, but here the friend of lawful redundancy would seem well within her rights to reject as impossible the envisioned 
threat; there is no clear reason to concede that two sets of fundamental, equipotent laws governing the same phenomena could - non-miraculously at least - diverge, and Leibniz certainly never suggests that there is a possible world that is so afflicted.

The critic of Leibniz's position could at this point sensibly retreat to firmer ground, putting pressure not on the coherence of two sets of metaphysically independent laws of nature, but rather on the apparent metaphysical extravagance that such a position would entail. She might reasonably argue that given a robust conception of the laws of nature, there could be no reason for postulating even two equally powerful, equally fundamental, laws of nature that accomplish exactly the same thing, much less for postulating two complete sets of laws of nature each of which would collectively yield exactly the same phenomena. The argument here would no longer be that Leibniz's view is impossible, but rather that it would violate a seemingly inviolable maxim of metaphysics - indeed of science more generally - namely, not to posit more entities where fewer will do.

As compelling as this plea for ontological parsimony is likely to seem today, it is worth noting that Leibniz has deeply embedded theological reasons for resisting it. Following a long tradition reaching back to at least Augustine, Leibniz maintains that existence itself is good. (In this way, he is afforded an answer to the old philosophical chestnut of why something rather than nothing exists.) But if existence itself is good, Leibniz is in a position to insist that in creating the best of all possible worlds God must seek to create as much being as possible. Leibniz is therefore committed to something like the inverse of Ockham's razor: the only possible reason for something's not existing is that it is inconsistent with other things that have an even greater claim to existence. ${ }^{17}$ Given this background, it is hard to see why Leibniz should be moved to abandon his view of lawful overdetermination by considerations of ontological extravagance. If 
two sets of laws, each grounded in its own set of metaphysical primitives, are mutually consistent, then by Leibniz's lights the presumption should be that both sets of laws exist. Indeed, given Leibniz’s background metaphysical picture, the real challenge posed by robust accounts of the laws of nature is not "Why two instead of only one?" but rather "Why only two?"18

Nonetheless while Leibniz's theodicy thus affords him a principled reason for simply embracing the charge of metaphysical extravagance, I think his position on the laws of nature does not require him to do so. To see why, it may be helpful to consider two points, one of which brings Leibniz closer to a robust metaphysical conception of the laws of nature, and one that distinguishes his position from the ones we have been considering thus far.

First, in distancing his own view from the position of occasionalism, Leibniz insists that the laws of nature must be grounded in genuine causal powers in the world. In the case of physics, those powers will be the derivative (but well-founded) active and passive powers attributable to bodies. Thus, in a letter to Basnage de Beauval of 1698, Leibniz writes:

It is not enough to say that God has made a general law; for besides this decree there must be a natural means of executing it; that is, it is necessary that what happens can be explained through the nature that God gives to things. (G IV 520/L 494)

We need not be detained here by the question of whether or not Leibniz's suggestion represents a deep criticism of the occaionalist's position. ${ }^{19}$ What is important for our purposes is simply that it highlights Leibniz's commitment to the laws of nature being metaphysically well-founded in the (intrinsic) causal powers of the world. In doing so, it brings Leibniz's position somewhat closer to metaphysically robust views on the laws of nature insofar as it distinguishes the 
Leibnizian account from Humean accounts according to which the laws represent mere patterns perhaps counterfactually stable patterns - in the mosaic of world events.

Second, while Leibniz thus believes that the laws of nature must be grounded in genuine causal powers of the world, he does not suggest that the laws of nature themselves are distinct postulates with respect to the fundamental ontology of the natural world - as Jolley's Malebranche, for example, suggests. Rather in keeping with his general conceptualism concerning relations, Leibniz must maintain that the laws of nature are mental abstractions from the fundamental natures that are intrinsically grounded in the bedrock constituents of the world. In short, for Leibniz, although there must be metaphysically robust primitives that ground the laws of nature, the laws of nature do not themselves add anything on the side of ontology. Leibniz is thus able to maintain that the multiplication of laws of nature need not presuppose a corresponding multiplication in metaphysical primitives. In this way, his picture is somewhat closer to Humean accounts than it might have seemed otherwise. For Leibniz, the laws of nature just are patterns - more specifically patterns abstracted by finite minds - with the crucial restriction that they must be well-founded on genuine causal powers in the world. ${ }^{20}$

With both points in place, it should be clear why Leibniz should not be troubled by the charge of metaphysical excess due to his postulation of two complete and equipotent sets of laws of nature. For the postulation of two such sets merely amounts to the suggestion that we may abstract two adequate patterns from the distribution of causal powers found in the world. Abstracting in one way, Leibniz maintains, reveals the efficient-causal order of the world; abstracting in another way reveals the teleological order of the world. Given Leibniz's picture of the laws of nature, the charge of metaphysical extravagance due to postulating two sets of laws of nature clearly falls away; even the most miserly ontologist can be expected to tolerate two sets 
of abstractions where one might otherwise suffice. To be sure, Leibniz’s suggestion remains audacious insofar as it is unclear that we can in fact discover two such promising sets of patterns in the world. But the boldness here is now recognizably not an ontological issue but a broadly empirical one, and furthermore one which, as we have seen, Leibniz takes steps - if only preliminary steps - to address through his work in optics and related problems.

Imperialistic Teleology?

If it is granted that good ontological sense can be made of Leibniz's postulation of two sets of equipotent laws, it might still be objected that Leibniz's laws - or at least their natural extensions - cannot be used to support his two realms doctrine. For it might be thought that one of Leibniz's two realms must be the more fundamental or basic, and the other a mere formal or heuristic consequence. Such is the thrust of an influential argument offered by David Hirschmann, who has suggested that Leibniz's introduction of teleological laws of nature undermines his commitment to efficient, broadly mechanical, models of explanation (Hirschmann 1988,159). Alluding to a widely accepted understanding of the relationship between "efficient laws" and "variational principles," he writes:

Of course, we know that Newton's laws of motion and a most determined principle, the Principle of Least Action (in its modern form) are interderivable. We may prefer, nevertheless, to think that Newton's laws give the physics and that the Least Action principle is a powerful mathematical representation of them, powerful because of the problems we can solve by it. Leibniz, for metaphysical reasons, is committed to the opposite. There is a purely architectonic reason for a most determined principle and so 
for whatever it entails. The kingdom of power's laws are dictated by the rules of wisdom ... The mechanization of the world picture is reconciled with piety by annexation. (Hirschmann 1988, 158-9) Hirschmann's argument for this striking conclusion appears to rest on two principal premises. The first is that within Leibniz's system there is a two-stage derivation of the efficient laws of nature beginning with God's ends in creating the world, and passing through the creation of teleological laws of nature. This derivation shows that the laws of the kingdom of power are not independent of the laws of the kingdom of wisdom. The second is that the non-independence of the efficient laws shows that they are in some sense less fundamental than the teleological laws, and therefore that in Leibniz's physics teleological explanations are in some sense more basic than their efficient cousins.

In assessing the threat to Leibniz's two realms doctrine posed by Hirschmann's line of argument, it should be helpful to consider each of his principal premises in turn. The first stage of the argument in support of the non-independence premise underscores the familiar point that for Leibniz the teleological laws of nature must themselves be derivable from God's providential design of the world. Thus Hirschmann writes:

The first stage of the argument, found in the Discourse, is an argument for design. The sufficient reason for any contingent truth lies in the fact that God, who is perfectly good and has unlimited knowledge, has chosen from the infinite number of possible worlds to make actual the one which is objectively the best. ... It is an exemplary case of rational explanation where motive and justification coincide. It is a final reason and that there should be the best is the end or final cause of God's creation of the world. Anything 
explained by showing that it is required for the optimal perfection of this world is explained by final cause. (Hirschmann 1988, 151f)

Hirschmann's first suggestion therefore is that Leibniz is committed to holding that the teleological laws of nature are derivable from God's ends in creating the best of all possible worlds. There is thus a teleological explanation of the teleological laws themselves. The usurpation by the kingdom of ends has, in Hirschmann's view, begun.

The second stage of the argument in support of the non-independence premise concerns the derivability of the efficient laws of nature from the teleological laws of nature. Noting that "The next stage in the argument goes back to the principle of perfection and its use in the Tentamen Anagogicum, ${ }^{21}$ Hirschman argues:

There are final causes in nature because the decree to create the best possible entails a principle of nature that the phenomena are most determined.... The one principle, to optimise perfection, determines uniquely. At the same time, it determines the specific laws according to which the phenomena occur. ... The sole principle that determines what exists is the principle of the most determined ways. [156] ... It seems unintelligible why God should order the phenomena in two ways when one will suffice. The fact is he does not provide two sets of laws. There is only one, provided by the principle that nature acts in the most determined ways. As I have said above, the solutions to the extremum hypotheses give the laws, in particular, the laws of motion [158] (Hirshmann, 1988, 156-158).

Having argued in the first stage that there is a teleological derivation of the principle that nature acts in the most determined ways, Hirschmann's second suggestion points out that if that principle is held to determine the world uniquely, it must be possible to derive from it not only 
local teleological laws of nature (such as that light takes the easiest path between its source and sink) but also the efficient laws of nature as well (such as the efficient laws of motion). Given that within Leibniz's system one can derive the efficient laws of nature from teleological laws of nature which in turn can be derived from divine ends, Hirschmann concludes that the efficient ordering of nature is not, after all, really independent of its teleological ordering.

While sympathetic to the broad outline of the derivation story that Hirschmann tells, I think we must nonetheless reject his closely related second premise to the effect that the nonindependence of the efficient laws from the teleological laws reveals them to be in some sense less fundamental or basic. And, indeed, I think we should resist Hirschmann's second premise not because the two sets of laws turn out to be more independent than we thought, but rather precisely because they are by Leibniz's lights so thoroughly, mutually, and symmetrically dependent. That is to say, far from insisting that the efficient and teleological laws of nature are completely independent, Leibniz should be understood as holding that the efficient and teleological orderings of the world are on a par with one another, and the defense of his view should be understood to rest on the claim that there is a perfect harmony between the world viewed in teleological terms and the world viewed in efficient-causal terms.

What lies behind Hirschmann's pessimistic reading of Leibniz's two realms doctrine, I suggest, is thus not so much the dependencies he highlights as the dependencies he overlooks. If we return to the first stage of his derivation we can readily see the symmetrical dependence implicit in Leibniz's position. For while it is true that the principle that nature always acts by the easiest and most determinate means can be seen to result from God's providential activity, Leibniz insists that the case is the same for the efficient laws of nature. Indeed, it is one of the hallmarks of Leibniz's mature physics that the laws of nature do not hold of brute necessity but 
rather depend on contingent, and good-making considerations such as the principle of the equality of cause and effect, and the principle of continuity. Within Leibniz's system the efficient and teleological orders of the world thus would appear to be on a par. God's act of creation is responsible for both sets of laws, but there is no reason to suppose that he intends one set primarily with the other set being, as it were, a mere consequence of the intended set. To Leibniz's way of thinking, God should be understood as intending to create only one world, which may count among its positive features the fact that it can be understood equally well as being governed by efficient and teleological laws of nature.

The situation is much the same with respect to the second stage of Hirschmann's derivation. He is clearly right to point out that in some sense the efficient laws of nature must be derivable from the teleological laws of nature if it is assumed that both are complete and equipotent. Although the development of variational principles has made such derivations more perspicuous, Leibniz no doubt would have readily conceded - indeed insisted upon - the at least in principle inter-derivability of teleological and efficient laws of nature. What he would have resisted - and understandably so - is that such inter-derivability shows that one set of laws must be more fundamental than the other. Although it is true that "the laws of mechanics must be derivable from a final cause principle" it is equally true that it is a consequence of the laws of mechanics that nature always acts in the most determinate ways - that is to say, that the teleological laws of nature must be derivable from the principles of mechanics. Given the symmetry of the case, there seems to be no reason to conclude that one ordering is more fundamental than the other. Inter-derivability, far from showing that the kingdom of wisdom encroaches upon the kingdom of power, thus only further reinforces the strict parallelism upon which Leibniz insists. 
It is still possible of course to object that since God's creative activity is itself goal directed, there is an inherent and inexpugnable bias in Leibniz's system in favor of the kingdom of wisdom. But this objection, I think, Leibniz could accept without doing any real damage to his two realms doctrine in its application to the natural world. For acknowledging God's providential design of the world need not in any way undermine the parallelism that Leibniz sees as holding within the created world itself. He could, in short, consistently hold that there is a perfect harmony between the efficient and teleological laws of nature, while granting that both sets of laws derive from God's wisdom rather than from God's power.

Nonetheless, to suggest that the establishment of the laws of nature is due primarily to God's wisdom rather than God's power is, I think, to fundamentally misunderstand Leibniz's thinking about the nature of God's free actions, and to underestimate Leibniz's commitment to the symmetry of final and efficient causation. In distancing himself from Descartes and Spinoza, Leibniz insists on a more than conceptual distinction between God's will and God's intellect. Without such a distinction, Leibniz fears, we undermine the objective goodness of God's actions, and set ourselves on the road towards a fatalistic necessitarianism (TS 334/AG 333-34). But no such worries beset the suggestion that there is only a conceptual distinction between God's will considered as an efficient cause and God's will considered as a final cause. Indeed, Leibniz tells us that "It is clear ... there is in God the reason not merely for the greatness and power in the world mechanism ... but also for the goodness and wisdom exerted in establishing it (UO 305/L 489). By focusing on God's concern for the good, Leibniz implies, we may emphasize the teleological flavor of God's activity, but with equal justification by focusing on the efficaciousness of God's will we may emphasize the efficient-causal flavor of God's activity. Put simply, God's will is simultaneously both an efficient cause and a final cause, and it is only 
by something like abstraction that one is emphasized at the expense of the other. In this way, the parallelism that underpins Leibniz's two realms doctrine with respect to the laws of nature holding within the world is nicely rounded out by a kind of parallelism in our understanding of God's very act of creation - an example of the sort of harmony within harmony that Leibniz not only delights in, but takes as a mark of profound truth.

\section{Lawful Overdetermination and Monadic Teleology}

Up to this point our focus has been on the tenability of Leibniz's account of teleology and teleological explanations within the domain of natural philosophy. In this last section, I would like to suggest that that account may in turn help to shed light on his views on the teleological unfolding of monads themselves. And, in particular, I would like to suggest that Leibniz's thinking about explanatory overdetermination in physical domains provides him with one way out of an apparent tension in his treatment of monadic development. The resolution of that tension, as we will see, implies that Leibniz’s most famous final-efficient harmony - the socalled pre-established harmony of mind and body-rests on a more subtle and interesting foundation than one might have otherwise suspected.

In approaching Leibniz's treatment of monadic teleology, it will be helpful to have three pieces of his account of monadic development clearly in view. First, Leibniz insists that we must attribute a primitive force, power, or nisus to each finite mental substance. Although he maintains that monads are metaphysically indivisible and simple, he nonetheless insists that like all created entities - they are subject to change, and indeed, to continuous change (Mon 10). Furthermore, Leibniz claims, the demands of continuous change require us to conceive of 
monads as being not only diverse at different stages of their careers, but also internally at each stage on pain of their otherwise having to "leap" from one stage to the next. He describes each stage of a monad as a complex perceptual state, which represents not only the states of all other substances in the universe, but also contains "marks and traces" of every future and past state of the substance to which it belongs (DM 6). For Leibniz, the primitive force attributed to monads serves as the immediate active cause driving the monad through its perceptual series from one cognitive state to the next. ${ }^{22}$

Second, Leibniz attributes to each monad its own distinct "law of the series" in accordance with which each monad unfolds under its own power in such a way as to fulfill its complete concept. Leibniz's suggestion that the development of each monad is governed by its own specific law - indeed by its own deterministic law - naturally invites a quasi-mechanical understanding of the unfolding of the perceptual states of a monad. ${ }^{23}$ Beginning with a complex perceptual state at some time $t_{1}$, a monad is driven by its own internal force, in accordance with its own law of the series, to assume its next complex perceptual state at time $t_{2}$. At $t_{2}$, the monad is again driven by its own internal force, again in accordance with its own law of the series, to assume its next complex perceptual state at time $t_{3}$, etc. ${ }^{24}$ The analogy to Leibniz's picture of the states of the physical world being driven in succession due to the activity of derivative forces in accordance with the laws of nature is irresistible, and no doubt intended on Leibniz's part.

Third, Leibniz maintains that the mental states of a monad unfold teleologically in accordance with "the motive of the good perceived by the understanding" (G 6:288). ${ }^{25} \mathrm{He}$ explicitly associates a monad's "internal principle which brings about the change or passage from one perception to another” with both Aristotelian formal natures and appetites - both associations, of course, carrying with them teleological connotations. Aristotle's formal natures 
were viewed not only as sources of internal activity, but also as sources of internal activity inherently directed towards the completion, or perfection, of the substances to which they belong. The language of appetite is, if anything, even more explicitly teleological, and in using it Leibniz clearly intends to capture the intuition that our mental lives unfold in a goal directed manner. Indeed, in the case of monads corresponding to the souls of human beings, he even goes so far as to identify the cumulative effect of appetites with the will itself (see, for example, $G$ 3:622; NE 192).

It is at this juncture, however, that one might begin to worry about the consistency of Leibniz's characterizations of monadic activity. And in particular one might worry that Leibniz is not entitled to present the monad both as unfolding in a teleological manner in accordance with the perceived good, and in a quasi-mechanical manner in accordance with its law of the series. Thus, for example, Robert Adams, after noting the teleological connotations suggested by Leibniz’s choice of the term “appetite,” warns:

[T] he language of “appetite” and "ends and means” may be somewhat misleading. It suggests the pursuit of a desired future state of affairs, but the action of a Leibnizian substantial form is more like what is sometimes called “acting on principle.” In Leibniz’s view the "internal principle" governing "the passage [of a substance] from one perception to another” is not based on the desirability of the later perception in itself, but rather on the following of certain laws of nature. (Adams 1994, 318)

Quoting with approval the passage from Adams, Jonathan Bennett sharpens the implicit objection as follows:

[L]eibniz's account of monadic appetite does not justify his redescriptions of it in such teleological terms as “final causes” and “ends and means.” His fundamental theory says 
only that the individual monad runs through its history in accordance with laws given to it by God, laws that govern the efficient causality of its unfolding. ... There seems to be no followable route from Leibniz's basic metaphysic to the notion of doing something for the sake of an end ... when his metaphysic is close at hand he has little to say about teleology except the blank assertion that final causes reign within the monad because of appetition. (Bennett 2005, 139)

The worry expressed here somewhat apologetically by Adams and more stridently by Bennett is that Leibniz is not really entitled to his claim that monads "act according to the laws of final causes, through appetitions, ends, and means.” The thought is clearly that Leibniz's quasimechanical descriptions of monadic development undermine his commitment to genuine monadic teleology. In fact, we might - paraphrasing Hirschmann - be tempted to cast the concern as implying that within the domain of psychology Leibniz's teleological construal of monads is reconciled with the scientific ideal of efficient, mechanical explanation by annexation.

That the mirror image of the worry that we saw arise in connection with Leibniz's defense of teleology in the domain of natural philosophy should arise in connection with his utilization of quasi-mechanical models in the domain of psychology is, of course, striking enough in its own right. But it might also provide us with a clue pointing in the direction of a more sympathetic understanding of Leibniz's views on monadic activity by suggesting that essentially the same considerations that made possible the reconciliation of derivative forces, efficient-mechanical laws, and optimization principles in the domain of natural bodies, might also make possible the reconciliation of primitive forces, quasi-mechanical models of monadic development, and the ascription of genuine teleology to finite minds. That is to say, in short, 
Leibniz's account of the explanatory overdetermination of the realm of nature might be thought to be mirrored by an explanatory overdetermination at the level of monads themselves.

According to such a picture, primitive forces would play the metaphysical role at the monadic level that we have seen derivative forces play at the level of the bodies studied by physics. They would be the created sources of genuine activity in the world satisfying the intuition that in addition to particular patterns in nature, there are also real causal powers that shape, determine or "necessitate” those patterns. Just as someone might hold that regular patterns of physical events - e.g. heavy bodies falling near the surface of the earth - must be underpinned by real causal powers in nature, so likewise Leibniz holds that the determined patterns of mental events occurring within finite minds must similarly be underpinned by real causal powers inherent in created minds. For Leibniz, primitive forces thus serve as the immediate causes of change within a monad in much the way that derivative forces serve as the immediate causes of change within the realm of the physical world.

As we have seen, however, Leibniz denies that the explanatory resources of physics are limited to causal powers or natures. Although such powers are essential for warding off metaphysical pitfalls, and satisfying certain natural intuitions, the mechanical philosophy suggests that we must also think of the world as being governed by regular laws of nature. Leibniz reasonably treats such laws not as additional fundamental elements of the physical world, but rather as patterns abstracted from the underlying causal powers that he takes to be determining the unfolding of physical events. Such a picture of the relationship between causal powers and the efficient laws of nature, however, in turn suggests a rather intuitive corollary picture of the relationship between primitive forces and a monad's "law of the series." Although a monad's primitive force is immediately responsible for its progression from one stage to 
another, one might reasonably suppose that its entire causal pattern, “recipe,” or "program,” as it were, could be considered in the abstract at least by an infinite intellect. If that pattern were particular enough to specify its every development, one might identify it with a monad's own specific "law of the series." The creation of a monad could thus be thought of as the creation of an initial state, or causal nexus, capable of producing an entire series of mental states in accordance with its own particular "law of the series."26

Although the possibility of conceiving of a monad as being generated from an initial state and a law of the series might seem to speak against its developing teleologically, Leibniz's work in optics once again suggests a strategy for reconciliation. Just as Leibniz suggests that we can think of the physical world both as unfolding in accordance with a mechanical pattern of efficient causes as well as a teleological pattern of final causes, so too we might think of a monad as being governed by both an efficient quasi-mechanical law of the series as well as a teleological principle of acting in accordance with the perceived good. Crucial here is the thought that the genuine causal powers postulated both at the physical and mental level are in and of themselves neutral with respect to being characterized as efficient or teleological. When subsumed under a regular pattern linking prior events to their immediate successors, such causal powers can be identified with non-teleological causes, and explanations can be generated by showing that a subsequent event follows from prior conditions and the efficient laws of nature. When subsumed under a regular pattern linking prior events to later events via reference to the expected outcomes of those events, such causal powers can be identified with teleological causes, and explanations can be generated by showing that a later event follows from prior conditions, expected outcome conditions, and the teleological laws of nature. From a God's eye perspective, at least, nothing should rule out being able to understand the progression of a monad 
from one state to another as following both in accordance with an efficient lawful pattern as well as in accordance with a teleological lawful pattern. The possibility of a lawful and explanatory overdetermination is no less coherent here than it is in the domain of optics and physics.

If all of this points towards a possible solution of the tension highlighted by Adams and Bennett, it also (perhaps surprisingly) suggests that Leibniz's most famous harmony - the preestablished harmony between mind and body - rests on a more subtle foundation than we might have otherwise imagined. In speaking of his proposed solution to the mind-body problem, Leibniz generally emphasizes the compatibility of thinking of the mind as unfolding in accordance with a teleological order even while thinking of the body as unfolding in accordance with an efficient causal order:

Souls act according to the laws of final causes, through appetitions, ends, and means. Bodies act according to the laws of efficient causes or of motions. And these two kingdoms, that of efficient causes and that of final causes, are in harmony with each other. (Mon 79/AG 223)

Leibniz, of course, had good reasons to highlight this particular final-efficient harmony. It represents the most intuitive presentation of his own position as an alternative to the solutions to the mind-body problem offered by the likes of Descartes, Spinoza and Malebranche. Furthermore, he might have reasonably hoped that he could win converts to his account of the mind's relationship to the body even from among those who would not accept - or even understand - his sophisticated views in optics and physics. Nonetheless, Leibniz's commitment to the legitimacy of teleological explanations even in the thick of doing natural philosophy suggests that his usual presentation of the pre-established harmony only tells part of the story. A more complete exposition, it seems, would reveal that the teleological and efficient harmony 
holding between the mind and body rests in turn on a pair of lawful and explanatory harmonies holding both within the domain of the mind and within the domain of the body itself. The explanatory parallelism of the mind and body is, in short, grounded in an explanatory parallelism of the mind as well as an explanatory parallelism of the body.

\section{Conclusion}

Leibniz was not, of course, the first to suggest that events in the natural world might be explained by appeal either to final or efficient causes - Aristotelians for example had long maintained that natural events could be explained both ways, and Leibniz himself implies that his own project can trace its origins to Plato (see, in particular, TS). Nonetheless, Leibniz's engagement with the new science of his time led him to a particularly novel, systematic, and intriguing picture of final-efficient explanatory overdetermination. In this essay, I have tried to provide a preliminary sketch of the origins, foundations, and implications of the picture he develops. Accordingly, I have first indicated an important source of Leibniz's two realms doctrine in his early attempts to reconcile Cartesian and Fermatian derivations of the laws of optics. Second, I have argued that that doctrine can be shown to rest on surprisingly sober foundations provided that Leibnizian laws are viewed as abstractions from the intrinsic, wellfounded, derivative forces attributable to bodies. And lastly, I have suggested that a proper understanding of Leibniz's position with respect to explanatory overdetermination within the domain of nature may provide insight into his understanding of monadic teleology and the supposed pre-established harmony between mind and body. ${ }^{27}$ 


\section{Bibliography}

Adams, Robert. 1994. Leibniz: Determinist, Theist, Idealist. New York: Oxford University Press.

Armstrong, D., 1978, A Theory of Universals, Cambridge: Cambridge University Press.

-----. 1983. What is a Law of Nature?, Cambridge: Cambridge University Press.

-----. 1991. "What Makes Induction Rational,” Dialogue, 30: 503-511.

-----. 1993. "The Identification Problem and the Inference Problem,” Philosophy and

Phenomenological Research, 53: 421-422.

Bennett, Jonathan. 1976. Linguistic Behaviour, Cambridge: Cambridge University Press. Reissued by Hackett Publishing Company: Indianapolis, 1989.

-----. 2001. Learning from Six Philosophers, in two volumes. Oxford: Oxford University

Press. Reference is to volume and page.

----. 2005. “Leibniz’s Two Realms,” in J. A. Cover and D. Rutherford (eds.), Leibniz, Nature and Freedom. New York: Oxford University Press.

Broad, C. D. 1975. Leibniz: An Introduction. Cambridge: Cambridge University Press.

Carroll, John. 1994. Laws of Nature (Cambridge: Cambridge University Press)

Cover, Jan and John Hawthorne. 1999. Substance and Individuation in Leibniz (New York: Cambridge University Press).

Della Rocca, Michael. 1996. “Spinoza’s Metaphysical Psychology,” in The Cambridge Companion to Spinoza, edited by Don Garrett, Cambridge: Cambridge University Press.

Descartes, René. 1897-1913. Oeuvres de Descartes, volumes 1-12, edited by Ch. Adam and P. Tannery, reprinted, Paris: J. Vrin, 1957-.

-----. 1965. Descartes: Discourse on Method, Optics, Geometry and Meteorology, translated and edited by P. J. Olscamp, Indianapolis: Bobbs-Merrill.

-----. 1985. The Philosophical Writings of Descartes, volumes 1-2, translated and edited by J. Cottingham, R. Stoothoff, D. Murdoch, Cambridge: Cambridge University Press.

Dretske, Fred. 1977. “Laws of Nature,” Philosophy of Science (44) 248-268.

Fermat, Pierre. 1891-1912. Oeuvres de Fermat, four volumes, edited by P. Tannery and Charles Henry, Paris.

Garber, Daniel. 1998. "Leibniz: Physics and Philosophy,” in The Cambridge Companion to Leibniz, edited by Nicholas Jolley. New York: Cambridge University Press. 
Goldstine, Herman. 1980. A History of the Calculus of Variations from the $17^{\text {th }}$ through the $19^{\text {th }}$ Century, New York: Springer-Verlag.

Gueroult, Martial. 1967. Leibniz: Dynamique et Métaphysique. Paris: AubierMontaigne.

Hirschmann, David. 1988. "The Kingdom of Wisdom and the Kingdom of Power in Leibniz,” Proceedings of the Aristotelian Society (88) 147-159.

Huygens, Christiaan. 1888-1950. Oeuvres completes de Christiaan Huygens, 22 volumes, La Haye: Société Hollandaise des Sciences. Reference is to volume and page.

Jolley, Nicholas. 2002. “Occasionalism and Efficacious Laws in Malebranche,” Midwest Studies in Philosophy, XXVI, 245-257.

-----. 2005. “Leibniz and Occasionalism” J. A. Cover and D. Rutherford (eds.), Leibniz, Nature and Freedom. New York: Oxford University Press, 121-134.

Korteweg, D. J. 1896. “Descartes et les manuscrits de Snellius d'après quelques documents nouveaux.” Revue de métaphysique et de morale (IV) 489-501.

Lange, Mark. 2000. Natural Laws in Scientific Practice (Oxford: Oxford University Press).

Lee, Sukjae. 2004. “Leibniz on Divine Concurrence,” The Philosophical Review (113:2) 203248.

Leibniz, G. W. 1677-80. “Two Sects of Naturalists,” in G 7:332-336.

-----. 1678 (- 1680/81?). “Definitiones Cogitationesque Metaphysicae,” in A VI, 4B, 1393-1405.

-----. 1682. “Unicum Opticae, Catoptricae \& Dioptricae Principium,” Acta Eruditorum, June. Reprinted in Acta Eruditorum, volume 1. New York: Johnson Reprint Corporation.

-----. 1686. "Discourse on Metaphysics,” in G 2:427-63. Reference is by section.

-----. 1695. “A Specimen of Dynamics,” in GM 6: 235-54. Reference is to section number.

-----. 1696. “Tentamen Anagogicum: An Anagogical Essay in the Investigation of Causes,” in G 7:270-79.

-----. 1697. "On the Ultimate Origination of Things," in G 7:302-8.

-----. 1697b. "Résumé of Metaphysics," in G 7:289-92. Reference is to section number.

-----. 1705. New Essays on Human Understanding, ed. and trans. P. Remnant and J. Bennett, Cambridge: Cambridge University Press.

-----. 1710. Theodicy, in G 6. Reference is to section number. English translation available in E. M. Huggard, Theodicy (New Haven: Yale University Press, 1952; reprint La Salle, Ill: Open Court, 1985). 
-----. 1714a. "Monadology,” in G 6:607-23. Reference is to section number.

-----. 1714b. “Principles of Nature and Grace,” in G 6:598-606. Reference is to section number.

-----. 1875-90. Die Philosophischen Schriften von Leibniz, 7 volumes, edited by C. I. Gerhardt, Berlin: Weidmann; reprinted Hildesheim: Georg Olms, 1978.

----- 1923-present. G. W. Leibniz: Samtliche Schriften und Briefe, edited by German Academy of Sciences, Berlin: Akademie Verlag. References are to series, volume and page.

-----. 1969. G. W. Leibniz: Philosophical Papers and Letters, $2^{\text {nd }}$ ed., translated and edited by L. E. Loemker, Dordrecht: Reidel.

-----. 1989. G. W. Leibniz: Philosophical Essays, translated and edited by R. Ariew and D. Garber, Indianapolis: Hackett.

-----. 1998. G. W. Leibniz: Philosophical Texts, translated and edited by R. Franks and R. Woolhouse, New York: Oxford University Press.

-----. 2001. The Labyrinth of the Continuum, Writings on the Continuum Problem, 16721686, translated and edited by Richard T. Arthur, New Haven: Yale University Press.

Lemons, Don. 1997. Perfect Form: Variational Principles, Methods, and Applications in Elementary Physics, Princeton, New Jersey: Princeton University Press.

Mach, Ernst. 1989. The Science of Mechanics, translated by Thomas J. McCormack, La Salle, Illinois: The Open Court Publishing Company.

Maudlin, Tim. Unpublished. “A Modest Proposal Concerning Laws, Counterfactuals, and Explanation.”

Maupertuis, P. 1698-1759. Oeuvres de Maupertuis, Lyons: Jean-Marie Bruyset. Reference to volume and page.

McDonough. 2007. “Leibniz on Natural Teleology and the Laws of Optics,” Philosophy and Phenomenological Research, forthcoming.

-----. Unpublished. "Leibniz: Creation and Conservation and Concurrence.”

Nagel, E. 1979. “Teleology Revisited,” reprinted in Teleology Revisited and Other Essays in the Philosophy of Science, New York: Columbia University Press.

Nelson, Alan. 2005. "Leibniz on Modality, Cognition, and Expression” in Alan Nelson, A Companion to Rationalism, Malden, MA: Blackwell Publishing.

Rutherford, Donald. 1993. "Natures, Laws and Miracles: The Roots of Leibniz's Critique of Occasionalism” in Steven Nadler, ed., Causation in Early Modern Philosophy. University Park: Penn State University Press.

-----. 2005. "Leibniz on Spontaneity,” in Donald Rutherford and J. A. Cover, eds., Leibniz: Nature and Freedom (Oxford: Oxford University Press).

Sabra, A. I. 1967. Theories of Light from Descartes to Newton, London: Olbourne. 
Sleigh, R. C. 1990. Leibniz \& Arnauld: A Commentary on Their Correspondence (New Haven: Yale University Press).

Spinoza, Benedict. 1661. Short Treatise on God, Man, and His Well-Being, edited and translated in E. Curley, The Collected Works of Spinoza, vol. 1. Princeton University Press 1985, 53-156.

-----. 1677. Ethics Demonstrated in Geometrical Order, edited and translated in E.

Curley, The Collected Works of Spinoza, vol. 1. Princeton University Press 1985, 408617.

Stöltzner, Michael. 1994. “Action Principles and Teleology,” in Inside Versus Outside, edited by Harald Atmanspracher and Gerhard Dalenoort, New York: Springer, 33-62.

-----. 1999. “To What Extent Does Formal Teleology Still Make Sense,” in Hermeneutics and Science, edited by M. Féhér, L. Ropolyi, and O. Kiss, Dordrecht: Kluwer, 227-246.

-----. 2000. "Le Principe de Moindre Action et les Trois Ordres de la Téléologie Formelle dans la Physique,” Archives de Philosophie (63) 621-655.

Tooley, Michael. 1977. “The Nature of Laws,” Canadian Journal of Philosophy (7) 667-698.

-----. 1987. Causation (Oxford: Oxford University Press)

Vossius, Isaac. 1662. De lucis natura et proprietate.

Whipple, John. Unpublished. "Continual Creation and Created Substance in the Leibnizian Metaphysics.”

Woodhouse, Robert. 1810. A History of the Calculus of Variations in the Eighteenth Century, New York: Chelsea Publishing Company.

Yourgrau, Wolfgang and Stanley Mandelstam. 1968. Variational Principles in Dynamics and Quantum Theory, Third Edition. London: Sir Isaac Pitman and Sons.

\footnotetext{
${ }^{1}$ I use the following abbreviations for Leibniz's texts (full references are provided in the bibliography): A= German Academy of Sciences (ed.) Gottfried Wilhelm Leibniz: Sämtliche Schriften und Briefe, 1926-; AG=R. Ariew and D. Garber (eds. and trans.) G. W. Leibniz:

Philosophical Essays, 1989; DC= G. W. Leibniz, “Definitiones Cogitationesque Metaphysicae,”
} 
1678; DM=G. W. Leibniz, "Discourse on Metaphysics,” 1686; FW= R. Franks and R. Woolhouse (eds.) G. W. Leibniz: Philosophical Texts, 1998; G=C. I. Gerhardt (ed.) Die Philosophischen Scriften von Gottfried Wilhelm Leibniz, 1875-90; L=L. Loemker (ed. and trans.), Gottfried Wilhelm Leibniz: Philosophical Papers and Letters $2^{\text {nd }}$ Edition, 1969); Mon=G. W. Leibniz, “Monadology,” 1714a; LC=Richard Arthur, ed and trans. G. W. Leibniz, The Labyrinth of the Continuum, Writings on the Continuum Problem, 2001; SD= G. W. Leibniz, “Specimen of Dynamics,” 1695; NE=G.W. Leibniz, “New Essays on Human Understanding” 1705; PNG=G. W. Leibniz, "Principles of Nature and Grace,” 1714b; TA=G. W. Leibniz, “Tentamen Anagogicum,” 1696; T=G. W. Leibniz, Theodicy, 1710; TS=G. W. Leibniz, “Two Sects of Naturalists” 1677-1680; UO=G. W. Leibniz, “On the Ultimate Origination of Things,” 1697. I have used the following abbreviations for Descartes's texts: AT= C. Adam and P. Tannery (eds.) Oeuvres des Descartes, 12 Volumes, 1897-1913; CSM=J. Cottingham, R. Stoothoff, and D. Murdoch (eds.) The Philosophical Writings of Descartes, Volumes 1 and 2, 1985.

${ }^{2}$ For further general discussion of Leibniz's two realms doctrine see Bennett (2005) and Broad (1975, 165-172).

${ }^{3}$ For discussion of these aspects of Leibniz’s physics, see for starters, Garber (1998) and Gueroult (1967).

${ }^{4}$ See, for example, DM, TA, UO, and TS passim.

${ }^{5}$ For a more detailed discussion of Leibniz’s reconciliation project, see McDonough (2007).

${ }^{6}$ See, especially, the first two discourses of Descartes’s Optics (AT 81-105/CSM 1:152-164).

For an unabridged edition of Descartes’s Optics in English, see his (1965, 65-173). It is perhaps 
worth noting that Descartes takes the second and third assumption to follow from the first given his understanding of the laws of motion and impact.

${ }^{7}$ Cf. Fermat's elegant proof that if light travels faster in one medium than in another, its quickest path will not be a straight line (Fermat 1891-1912, 2:457-63).

${ }^{8}$ Assuming (at least) that the reflecting surface is planar and the medium uniform and isotropic. As we will see below, Leibniz also considers more complicated cases as well.

${ }^{9}$ Like many others - including Aristotle of course - Leibniz does not assume that the attribution of ends in nature presupposes a mental awareness in nature of those ends.

${ }^{10}$ For arguments that they are not genuinely teleological, see especially Bennett (1976, 75-78; 2001, 1:271-2), Nagel (1979, 285-290), and Yourgrau and Mandelstam (1968, 176).

McDonough 2007 attempts to defend Leibniz’s characterization against the charges that (i) it violates commonsense and linguistic intuition, (ii) would make the distinction between the teleological and non-teleological otiose, and (iii) fails to appreciate the mathematical equivalence of laws expressed in terms of variational and non-variational equations. For an interesting discussion of other related issues, see Stöltzner (1994, 1999, and 2000).

${ }^{11}$ Dissatisfaction with Descartes's proofs, and surrounding circumstances, soon led to the charge that Descartes had, in fact, learned the law from Snell's work while residing in Holland. Although the charge was first publicly expressed by Isaac Vossius in 1662, doubts concerning the originality of Descartes’s discovery were shared by both Huygens and Leibniz (see, Vossius 1662, 36; Huygens 1888-1950, 8:9 and 10:405; Leibniz TA 274/L 479-80 and DM 22/L 317-18). In spite of the array of talent aligned against Descartes, the evidence seems at best inconclusive. For further discussion of the dispute, see Korteweg (1896, 489-501) and Sabra (1967, 99-116). 
${ }^{12}$ For general discussion of the development of such problems see, especially, Mach (1989), Lemons (1997), and Yourgrau (1968); for discussion of them in connection with Leibniz in particular, see McDonough (2007).

${ }^{13}$ For more on the history of the development of the calculus of variations, see Goldstine (1980), Mach (1989), and Woodhouse (1810).

${ }^{14}$ One needn't, of course, suppose that this is Leibinz's only route into his two realms doctrine. In currently unpublished work, Daniel Garber, for example, emphasizes the importance of theological and anti-spinozistic reasons leading Leibniz to his two realms doctrine.

${ }^{15}$ In what follows, I will assume that both sets of laws hold exactly, and bracket concerns arising from the possibility of miracles. As Alan Nelson pointed out to me, if Leibniz were willing to allow that the laws of nature could hold with differing exactness, or that they admit of different miraculous exceptions, the task of defending his postulation of two sets of "generically" complete laws would be that much easier.

${ }^{16}$ For three classic robust accounts, see Armstrong (1978, 1983, 1991, 1993), Dretske (1977), and Tooley $(1977,1987)$. See also the more recent non-reductive accounts offered by Carroll (1994) and Lange (2000). Finally, for a view that is interestingly similar in important respects to the view attributed to Malebranche by Jolley, see Maudlin (unpublished).

${ }^{17}$ See, for example, G III 444; G IV 294, 404-405; NE 438, and UO 303/L 487.

${ }^{18} \mathrm{Cf}$. Spinoza's commitment to there being infinitely many attributes $(16771 \mathrm{p} 9,1 \mathrm{p} 11 \mathrm{~d}, 2 \mathrm{p} 7 \mathrm{~s}$; and 1661, 64n).

${ }^{19}$ On this issue, see Jolley (2005) and Rutherford (1993).

${ }^{20}$ Leibniz's understanding of the laws of nature as abstractions from causal natures has been more widely discussed in connection with his account of miracles. In brief, Leibniz holds that a 
miracle occurs where something happens that exceeds the causal powers of created beings (AG 83). For discussion of Leibniz's account of laws in relation to miracles, see especially Adams (1994, 85-94), Sleigh (1990, 162-170), and Rutherford (1993). For a stimulating account of Leibnizian abstraction in connection with his account of eternal truths, see Nelson (2005). ${ }^{21}$ Beginning at Hirschmann $(1988,152)$.

${ }^{22}$ Because it would only distract from the central point, I set aside here Leibniz’s commitment to divine concurrence. For discussion, texts, and references, see especially Lee (2004). For an account that attempts to preserve a more robust conception of secondary causation for Leibniz's created substances, see McDonough (unpublished).

23 "Quasi-mechanical" rather than "mechanical" because the operations of the mind cannot, according to Leibniz, be understood in terms of shapes and motions. See, for example, Mon 17. ${ }^{24}$ This, of course, is but a crude first pass: a more careful account would have to take into account (at a minimum) Leibniz's apparent commitment to the continuous nature of monadic change and time's being non-basic in his mature metaphysics. Such subtleties, however, should not be necessary for our purposes. For an interesting discussion of these topics, and a route into the literature, see John Whipple (unpublished).

${ }^{25}$ As Donald Rutherford has noted, when Leibniz discusses monadic teleology he sometimes has in mind a monad's tendency towards an objectively optimal state of affairs, and sometimes a tendency towards a merely perceived, or apparently, optimal state of affairs. Corresponding to these two conceptions of teleology we might, following Rutherford, distinguish between the "laws of natural teleology" and the "laws of desired teleology," where the former will be applicable to all monads and the latter will be reserved for monads to which will and understanding can be attributed. Although the language of acting for a "perceived good," or for 
the “apparent good,” might thus be strained, or even inappropriate, in the case of non-reflective monads, since all monads unfold in such a way as realize their full natures, and thereby realize the perfection of the world, their activity for Leibniz will nonetheless be describable in terms of teleological laws. See, Rutherford (2005, 166-168).

${ }^{26}$ See, for example, Cover and Hawthorne (1999, 214-252).

${ }^{27}$ I would like to thank Paul Hoffman, Nicholas Jolley, Alison Simmons, John Whipple, and especially Alan Nelson for their helpful comments and discussions in connection with this paper. 